\title{
PEMBERIAN ZPT DEKAMON DAN PUPUK DAUN TERHADAP PERTUMBUHAN VEGETATIF BIBIT KAKAO (Theobroma cacao L.)
}

\author{
Muhammad Muaz Munauwar ${ }^{1}$, Husainah Yusuf ${ }^{2}$, Nursiah $^{3}$ \\ ${ }^{1}$ Dosen Program Studi Agroteknologi, Fakultas Pertanian Universitas Samudra \\ ${ }^{2}$ Dosen Program Studi Agroteknologi, Fakultas Pertanian Universitas Gunung Leuser \\ ${ }^{3}$ Alumni Program Studi Agroteknologi, Fakultas Pertanian Universitas Gunung Leuser
}

\begin{abstract}
ABSTRAK
Penelitian ini bertujuan untuk mengetahui pengaruh pemberian ZPT Dekamon dan Pupuk Daun Gandasil baik secara faktor tunggal maupun interaksi terhadap pertumbuhan bibit tanaman kakao. Penelitian ini telah dilaksanakan di Desa Batumbulan Asli Kecamatan Baussalam Kabupaten Aceh Tenggara. Penelitian ini menggunakan Rancangan Acak Kelompok (RAK) pola faktorial yang terdiri dari dua faktor, yaitu konsentrasi ZPT Dekamon (D) dan kosenstrasi pupuk Gandasil (G) yang masingmasing terdiri atas 3 taraf perlakuan. Faktor Dosis ZPT Dekamon : $\mathrm{D}_{1}=2 \mathrm{ml} / \mathrm{L}, \mathrm{D}_{2}=4 \mathrm{ml} / \mathrm{L}, \mathrm{D} 3=6$ $\mathrm{ml} / \mathrm{L}$. Faktor Konsentrasi Gandasil : $\mathrm{G}_{1}=1 \mathrm{gr} / \mathrm{L}, \mathrm{G}_{2}=2 \mathrm{gr} / \mathrm{L}, \mathrm{G}_{3}=3 \mathrm{gr} / \mathrm{L}$. Variabel yang diamati adalah tinggi tanaman $(\mathrm{cm})$, diameter pangkal batang $(\mathrm{cm})$, jumlah daun (helai), lebar daun $(\mathrm{cm})$, dan panjang daun $(\mathrm{cm})$. Pemberian ZPT Dekamon tidak berpengaruh nyata terhadap tinggi tanaman, jumlah daun, lebar daun dan panjang daun, tetapi berpengaruh nyata terhadap diameter batang umur 30 dan 60 HST. Pemberian pupuk daun Gandasil tidak berpengaruh nyata terhadap tinggi tanaman, diameter batang, jumlah daun, luas daun dan panjang daun pada semua umur.
\end{abstract}

Kata kunci : ZPT dekamon, pupuk daun, kakao

\section{PENDAHULUAN Latar Belakang Penelitian}

Kakao (Theobroma cacao L.) merupakan salah satu jenis tanaman perkebunan yang terus mendapat perhatian untuk dikembangkan. Adapun aspek yang paling diperhatikan dalam usaha peningkatan jumlah produksi dan mutu hasil adalah penggunaan jenis-jenis kakao unggul dalam pembudidayaan tanaman kakao. Saat ini terdapat sejumlah jenis kakao unggul yang sering digunakan dalam budidaya kakao (Direktorat Jenderal Perkebunan, 2009).

Pembibitan tanaman kakao umumnya dilakukan didalam polibag, sebelum dipindahkan umumnya biji-biji tersebut dikecambahkan dalam bedengan persemaian, biji akan berkecambah pada umur 4-5 hari, biji yang belum berkecambah dapat dibiarkan 2-3 hari sebelum dibuang sebagai biji afkir (Siregar, 2014).

Pengatur pertumbuhan atau hormon tidak mengandung banyak zat makanan tetapi mempengaruhi pertumbuhan dan perkembangan. Zat pengatur tumbuh dan hormon lazimnya diproduksi secara alami dalam tumbuhan. Auksin, sitokinin, giberelin, dan etilen merupakan zat yang digunakan sebagai hormon atau pengatur pertumbuhan (Witjaksana, 2000).

Menurut (Suhadi, 2002) sitokinin yang sering digunakan adalah Dekamon, karena selain harganya relatif murah efektifitasnya juga tinggi, dekamon adalah zat pengatur tumbuh dari golongan sitokinin yang didefinisikan sebagai senyawa organik dan bila dikombinasikan dengan senyawa auksin akan mendorong pembelahan sel tanaman.

Dalam pemberian zat pengatur tumbuh konsentrasi yang tepat akan mempengaruhi pertumbuhan tanaman, sebaliknya jika berlebihan akan menghambat atau mematikan tanaman, pada 0-2 bulan awal pertumbuhan tanaman sangat baik diberikan zat pengatur tumbuh (Suherman, 2007). 
Gandasil D adalah pupuk majemuk yang $100 \%$ larut dalam air dengan kandungan unsur hara sebagai $22 \% \mathrm{~N}$ yang terdiri $6 \%$ Nitrat, $2 \%$ Ammonium dan $14 \%$ Urea. Selain itu juga mengandung $11 \quad \% \quad \mathrm{P}_{2} \mathrm{O}_{5}, 22 \quad \% \quad \mathrm{~K}_{2} \mathrm{O}$ dan dilengkapi dengan unsur hara mikro Fe, Mn, B, $\mathrm{Zn}, \mathrm{Cu}$, Mo (Cahyono, 2010).

Gandasil D dengan formula khusus memacu pertumbuhan vegetatif dan memperbanyak tunas baru, larut secara sempurna dalam air dan dapat diaplikasikan bersama-sama dengan pestisida. Gandasil D dapat diaplikasikan melalui daun dengan cara disemprotkan atau melalui akar dengan cara penyiraman pada tanah dan cara hidroponik (Lingga, 2004).

\section{Tujuan Penelitian}

Untuk mengetahui pengaruh pemberian ZPT Dekamon dan Pupuk Daun Gandasil baik secara faktor tunggal maupun interaksi terhadap pertumbuhan bibit tanaman kakao.

\section{Hipotesis}

Pemberian ZPT Dekamon dan Pupuk Daun Gandasil berpengaruh nyata terhadap pertumbuhan bibit tanaman kakao. Serta terdapat interaksi antara kedua perlakuan.

\section{METODE PENELITIAN Tempat dan Waktu Penelitian}

Penelitian ini telah dilaksanakan di desa Batumbulan Asli Kecamatan Baussalam Kabupaten Aceh Tenggara dari bulan Agustus 2016 sampai dengan bulan Nopember 2016. Lokasi penelitian terletak pada ketinggian tempat 200 meter di atas permukaan laut.

\section{Bahan dan Alat}

Bahan : benih cacao varietas Criollo yang diperoleh dari Dinas Perkebunan Aceh Tenggara yang berasal dari Balai Penelitian RISPA medan, tanah lapisan atas (top soil), Zat Pengatur Tumbuh Dekamon, Pupuk Gandasil D, Polybag ukuran $18 \times 25 \mathrm{~cm}$, pestisida $85 \mathrm{~S}$ dan Dithane M-45.
Alat : cangkul, pisau, tali, gembor, mikrometer, meteran, alat tulis menulis.

\section{Metode Penelitian}

Penelitian ini menggunakan Rancangan Acak Kelompok (RAK) pola faktorial yang terdiri dari dua factor, yaitu konsentrasi ZPT Dekamon (D) dan kosenstrasi pupuk Gandasil (G) yang masing-masing terdiri atas 3 taraf perlakuan. Faktor Dosis ZPT Dekamon : $\mathrm{D}_{1}=$ $2 \mathrm{ml} / \mathrm{L}, \quad D_{2}=4 \mathrm{ml} / \mathrm{L}, \quad \mathrm{D} 3=6 \mathrm{ml} / \mathrm{L}$. Faktor Konsentrasi Gandasil : $\mathrm{G}_{1}=1 \mathrm{gr} / \mathrm{L}, \mathrm{G}_{2}=2 \mathrm{gr} / \mathrm{L}$, $\mathrm{G}_{3}=3 \mathrm{gr} / \mathrm{L}$. Diperoleh 9 kombinasi perlakuan dan 27 percobaan, penempatan perlakuan pada satuan percobaan dilakukan secara acak. Model matematik yang digunakan dalam analisa data penelitian ini adalah :

$Y i j k=\mu+\beta i+D j+G k+(D G) j k+\varepsilon i j k$

Data hasil penelitian di analisis dengan sidik ragam. Hasil analisis sidik ragam yang berpengaruh sangat nyata atau nyata terhadap parameter yang diamati, dilanjutkan dengan uji Beda Nyata Terkencil (BNT) taraf 5\%.

\section{Pelaksanaan Penelitian \\ Persiapan Media Tumbuh}

Tanah untuk pengisian polybag diambil dari tanah lapis atas (top soil). Setelah diayak tanah dicampur dengan kompos secara merata sesuai dengan taraf perlakuan yang dicobakan kemudian campuran tanah dan pupuk kompos tersebut diisi kedalam polybag. Selanjutnya disusun sesuai dengan bagan percobaan, dimana pada setiap plot percobaan terdapat 6 polybag.

\section{Pembibitan}

Tempat pembibitan dibuat dari kotak papan segi empat dengan ukuran panjang $1 \mathrm{~m}$ dan tinggi $10 \mathrm{~cm}$. Kedalam kotak penelitian diisi dengan pasir setinggi $10 \mathrm{~cm}$. Benih yang telah dipilih dari buah yang sudah cukup matang dan diambil dari bagian tengahnya, kemudian digosok denga abu sekam agar bebas dari lendir dan dicuci. Benih ditanam dalam media pasir dengan jarak $5 \times 5 \mathrm{~cm}$ dan disiram merata. Setelah 4 hari bibit dipindahkan kedalam polybag. 


\section{Penanaman Bibit}

Penanaman bibit dilakukan pada sore hari, namun sebelumnya media tumbuh disiram dengan maksud untuk menciptakan lingkungan yang baik bagi kecambah yang akan ditanam. Pembuatan lubang tanah dibuat dengan menusukkan ibu jari ke tanah sedalam $(2 \mathrm{~cm})$. Kecambah yang akan ditaman sebelumnya disortir dahulu untuk memilih kecambah yang baik dengan bentuk dan ukuran yang sama.

\section{Pemeliharaan}

Pemeliharaan tanaman meliputi penyiraman, penyiangan serta pengendalian hama dan panyakit. Penyiraman dilakukan setiap pagi dan sore hari pada permukaan polybag. Penyiangan dilakukan secara manual dengan mencabut gulma yang ada dalam polybag dua minggu sekali. Untuk menjaga serangan hama dan penyakit, maka tindakan preventif yang dilaksanakan adalah dengan pestisida Sevin $85 \mathrm{~S}$ dan Dithane M-45 dengan aplikasi 30 hari sekali.

\section{APLIKASI PERLAKUAN}

Pemberian ZPT Dekamon dan Pupuk Daun Gandasil sesuai dengan taraf konsentrasi yang dicobakan, diberikan pada umur 5, 35 dan 65 hari setelah tanam. Dengan penyemprotan kepermukaan helai bagian bawah dan atas sampai merata dengan menggunakan hand sprayer.

\section{Pengamatan}

Variabel yang diamati selama penelitian berlangsung adalah tinggi tanaman $(\mathrm{cm})$, diameter pangkal batang $(\mathrm{cm})$, jumlah daun (helai), lebar daun $(\mathrm{cm})$, dan panjang daun $(\mathrm{cm})$.

\section{HASIL}

\section{Tinggi Tanaman}

Hasil pengamatan terhadap tinggi tanaman bibit kakao menunjukkan bahwa perlakuan pemberian ZPT Dekamon dan Pupuk Daun Gandasil tidak berpengaruh nyata terhadap tinggi tanaman kakao pada umur 30, 60 dan90 hari setelah tanam.

Table 1. Tinggi bibit kakao akibat perlakuan pemberian pupuk ZPT Dekamon dan Pupuk Daun Gandasil pada umur 30, 60 dan 90 HST $(\mathrm{cm})$

\begin{tabular}{|c|c|c|c|c|}
\hline \multirow{3}{*}{ Dosis ZPT } & \multicolumn{3}{|c|}{ Konsentrasi Pupuk Daun } & \multirow{3}{*}{ Rataan } \\
\hline & G1 & $\mathrm{G} 2$ & G3 & \\
\hline & \multicolumn{3}{|c|}{30 HST } & \\
\hline D1 & 13,67 & 15,23 & 12,22 & 13,71 \\
\hline $\mathrm{D} 2$ & 13,67 & 13,72 & 12,81 & 13,40 \\
\hline D3 & 13,22 & 13,28 & 13,61 & 13,37 \\
\hline \multirow[t]{2}{*}{ Rataan } & 13,52 & 14,08 & 12,88 & \\
\hline & \multicolumn{3}{|c|}{$60 \mathrm{HST}$} & \\
\hline D1 & 14,47 & 16,30 & 13,21 & 14,66 \\
\hline D2 & 14,42 & 14,89 & 14,17 & 14,49 \\
\hline D3 & 14,47 & 14,04 & 13,89 & 14,13 \\
\hline \multirow[t]{2}{*}{ Rataan } & 14,45 & 15,08 & 13,76 & \\
\hline & \multicolumn{3}{|c|}{$90 \mathrm{HST}$} & \\
\hline D1 & 15,10 & 15,46 & 13,73 & 14,76 \\
\hline D2 & 14,92 & 15,49 & 15,02 & 15,14 \\
\hline D3 & 15,14 & 14,72 & 15,21 & 15,02 \\
\hline
\end{tabular}



Rataan
15,05
15,22
14,65

Keterangan : Angka yang diikuti huruf yang berbeda pada kolom yang sama berbeda nyata pada taraf 5 \% (huruf kecil)

Diameter Batang

Perlakuan pemberian pupuk ZPT Dekamon pada 30 dan 60 HST berpengaruh nyata terhadap diameter batang bibit kakao, Tetapi tidak berpengaruh nyata pada 90 HST. Sedangkan pemberian Pupuk Daun Gandasil tidak berpengaruh nyata terhadap diameter batang tanaman kakao pada umur 30, 60 dan 90 hari setelah tanam.

Tabel 2. Diameter batang bibit kakao akibat perlakuan pemberian pupuk ZPT Dekamon dan Pupuk Daun Gandasil pada umur 30, 60 dan 90 HST $(\mathrm{cm})$

\begin{tabular}{|c|c|c|c|c|}
\hline \multirow{3}{*}{ Dosis ZPT } & \multicolumn{3}{|c|}{ Konsentrasi Pupuk Daun } & \multirow{3}{*}{ Rataan } \\
\hline & G1 & $\mathrm{G} 2$ & G3 & \\
\hline & \multicolumn{3}{|c|}{30 HST } & \\
\hline D1 & 2,56 & 2,50 & 2,38 & $2,48 \mathrm{~b}$ \\
\hline D2 & 2,48 & 2,43 & 2,34 & $2,42 \mathrm{~b}$ \\
\hline D3 & 2,00 & 1,83 & 2,28 & $2,04 \mathrm{a}$ \\
\hline \multirow[t]{2}{*}{ Rataan } & 2,35 & 2,25 & 2,33 & \\
\hline & \multicolumn{3}{|c|}{$60 \mathrm{HST}$} & \\
\hline D1 & 3,16 & 3,14 & 3,22 & $3,17 \mathrm{~b}$ \\
\hline D2 & 2,89 & 2,89 & 2,90 & $2,89 \mathrm{a}$ \\
\hline D3 & 2,58 & 2,52 & 2,73 & $2,61 \mathrm{a}$ \\
\hline \multirow[t]{2}{*}{ Rataan } & 2,88 & 2,85 & 2,95 & \\
\hline & \multicolumn{3}{|c|}{$90 \mathrm{HST}$} & \\
\hline D1 & 3,62 & 3,78 & 3,88 & 3,76 \\
\hline D2 & 3,54 & 3,56 & 3,67 & 3,59 \\
\hline D3 & 3,44 & 3,27 & 3,64 & 3,45 \\
\hline Rataan & 3,53 & 3,54 & 3,73 & \\
\hline
\end{tabular}

Keterangan : Angka yang diikuti huruf yang berbeda pada kolom yang sama berbeda nyata pada taraf $5 \%$ (huruf kecil)

\section{Jumlah Daun}

Perlakuan konsentrasi ZPT dekamon dan konsentrasi pupuk daun Gandasil tidak berpengaruh nyata terhadap jumlah daun tanaman kakao pada umur 30, 60 dan 90 HST.
Tabel 3. Jumlah daun bibit kakao akibat perlakuan pemberian pupuk ZPT Dekamon dan Pupuk Daun Gandasil pada umur 30, 60 dan 90 HST (helai)

\begin{tabular}{lcccc}
\hline & \multicolumn{3}{c}{ Konsentrasi Pupuk Daun } & \multirow{2}{*}{ Rataan } \\
\cline { 2 - 3 } Dosis ZPT & G1 & G2 & G3 & \\
\cline { 2 - 4 } & \multicolumn{3}{c}{$30 \mathrm{HST}$} \\
D1 & 4,22 & 4,56 & 4,22 & 4,33 \\
D2 & 4,44 & 4,78 & 3,67 & 4,30 \\
D3 & 4,11 & 4,00 & 4,78 & 4,30 \\
\hline \multicolumn{2}{c}{ Rataan } & 4,26 & 4,45 & 4,22 \\
\hline \multicolumn{3}{c}{$60 \mathrm{HST}$} \\
\hline
\end{tabular}




\begin{tabular}{|c|c|c|c|c|}
\hline D1 & 8,11 & 6,78 & 7,44 & 7,44 \\
\hline D2 & 8,78 & 7,22 & 8,00 & 8,00 \\
\hline D3 & 7,78 & 6,78 & 8,33 & 7,63 \\
\hline Rataan & 8,22 & 6,93 & 7,92 & \\
\hline \multicolumn{5}{|c|}{$90 \mathrm{HST}$} \\
\hline D1 & 11,67 & 10,89 & 10,89 & 11,15 \\
\hline D2 & 10,67 & 11,56 & 10,44 & 10,89 \\
\hline D3 & 11,00 & 10,00 & 11,11 & 10,70 \\
\hline Rataan & 11,11 & 10,82 & 10,81 & \\
\hline
\end{tabular}

Keterangan : Angka yang diikuti huruf yang berbeda pada kolom yang sama berbeda nyata pada taraf $5 \%$ (huruf kecil)

\section{Lebar Daun}

Pengamatan lebar daun tanaman bibit kakao pada umur 30, 60 dan 90 hari setelah tanam menunjukkan bahwa perlakuan pemberian ZPT Dekamon dan Pupuk Daun Gandasil tidak berpengaruh nyata terhadap lebar daun tanaman kakao pada umur 30, 60 dan90 hari setelah tanam.

Tabel 4. Lebar daun bibit kakao akibat perlakuan pemberian pupuk ZPT Dekamon dan Pupuk Daun Gandasil pada umur 30, 60 dan 90 HST (cm)

\begin{tabular}{|c|c|c|c|c|}
\hline \multirow{3}{*}{ Dosis ZPT } & \multicolumn{3}{|c|}{ Konsentrasi Pupuk Daun } & \multirow{3}{*}{ Rataan } \\
\hline & G1 & G2 & G3 & \\
\hline & \multicolumn{3}{|c|}{$30 \mathrm{HST}$} & \\
\hline D1 & 4,32 & 4,80 & 3,62 & 4,25 \\
\hline D2 & 4,16 & 3,96 & 4,13 & 4,08 \\
\hline D3 & 5,17 & 4,24 & 4,19 & 4,53 \\
\hline Rataan & 4,55 & 4,33 & 3,98 & \\
\hline \multicolumn{5}{|c|}{$60 \mathrm{HST}$} \\
\hline D1 & 5,93 & 5,72 & 6,08 & 5,91 \\
\hline D2 & 6,76 & 4,70 & 5,31 & 5,59 \\
\hline D3 & 5,70 & 6,11 & 5,69 & 5,83 \\
\hline Rataan & 6,13 & 5,51 & 5,69 & \\
\hline \multicolumn{5}{|c|}{$90 \mathrm{HST}$} \\
\hline D1 & 7,44 & 7,86 & 7,50 & 7,60 \\
\hline D2 & 7,98 & 6,66 & 6,89 & 7,18 \\
\hline D3 & 7,46 & 7,54 & 7,78 & 7,59 \\
\hline Rataan & 7,63 & 7,35 & 7,39 & \\
\hline
\end{tabular}

Keterangan : Angka yang diikuti huruf yang berbeda pada kolom yang sama berbeda nyata pada taraf $5 \%$ (huruf kecil)

Panjang Daun

Dari pengamatan Panjang daun bibit kakao pada umur 30, 60 dan 90 hari setelah tanam menunjukkan bahwa perlakuan pemberian ZPT Dekamon dan Pupuk Daun Gandasil tidak berpengaruh nyata terhadap panjang daun tanaman kakao pada umur 30, 60 dan 90 hari setelah tanam.

Tabel 5. Panjang daun bibit kakao akibat perlakuan pemberian pupuk ZPT Dekamon dan Pupuk Daun Gandasil pada umur 30, 60 dan 90 HST $(\mathrm{cm})$ 


\begin{tabular}{|c|c|c|c|c|}
\hline \multirow{3}{*}{ Dosis ZPT } & \multicolumn{3}{|c|}{ Konsentrasi Pupuk Daun } & \multirow{3}{*}{ Rataan } \\
\hline & G1 & G2 & G3 & \\
\hline & \multicolumn{3}{|c|}{$30 \mathrm{HST}$} & \\
\hline D1 & 10,28 & 11,50 & 9,56 & 10,45 \\
\hline D2 & 10,32 & 9,33 & 8,94 & 9,53 \\
\hline D3 & 9,28 & 9,89 & 11,06 & 10,08 \\
\hline \multirow[t]{2}{*}{ Rataan } & 9,96 & 10,24 & 9,85 & \\
\hline & \multicolumn{3}{|c|}{$60 \mathrm{HST}$} & \\
\hline D1 & 14,41 & 13,19 & 14,58 & 14,06 \\
\hline D2 & 15,21 & 11,12 & 11,8 & 12,71 \\
\hline D3 & 13,18 & 13,48 & 14,59 & 13,75 \\
\hline \multirow[t]{2}{*}{ Rataan } & 14,27 & 12,60 & 13,66 & \\
\hline & \multicolumn{3}{|c|}{$90 \mathrm{HST}$} & \\
\hline D1 & 16,94 & 20,44 & 18,61 & 18,66 \\
\hline D2 & 17,80 & 19,44 & 15,83 & 17,69 \\
\hline D3 & 19,33 & 18,39 & 18,94 & 18,89 \\
\hline Rataan & 18,02 & 19,42 & 17,79 & \\
\hline
\end{tabular}

Keterangan : Angka yang diikuti huruf yang berbeda pada kolom yang sama berbeda nyata pada taraf $5 \%$ (huruf kecil)

\section{PEMBAHASAN}

\section{Pengaruh Pemberian ZPT Dekamon}

Terhadap Pertumbuhan Bibit Kakao

Dari hasil penelitian yang dilakukan, dosis ZPT Dekamon(D) yang digunakan (2, 4 dan 6 ltr/ha) tidak memberi pengaruh yang nyata terhadap tinggi bibit, jumlah daun, lebar daun dan panjang daun pada umur 30, 60 dan 90 hari setalah tanam. Namun berpegaruh nyata terhadap diameter batang pada umur 60 hari setelah tanam dan berpengaruh sangat nyata pada unur 90 hari setelah tanam. Salah satu faktor yang sangat mempengaruhi keberhasilan penggunaan zat pengatur tumbuh bagi tanaman adalah konsentrasi pemberiannya. Apabila konsentrasi yang digunakan terlalu tinggi menyebabkan kematian bagi tanaman, sedangkan konsentrasi pemberian yang terlalu rendah menyebabkan menurunnya efek zat pengatur tumbuh tersebut (Cahyono, 2010). Akibat konsentrasi yang diberikan terlalu rendah maka diduga hal tersebut yang menyebabkan sebagian besar parameter pengamatan menunjukkan hasil tidak berbeda nyata.

\section{Pengaruh Konsentrasi Pupuk Daun Gandasil Terhadap Pertumbuhan Bibit Kakao}

Dari hasil analisis statistik menunjukkan bahwa pupuk daun Gandasil dengan konsentrasi 1, 2 dan 3 gr/ltr air tidak berpengaruh nyata terhadap tinggi bibit, diameter batang, jumlah daun, lebar daun dan panjang daun pada umur 30,60 dan 90 hari setelah tanam. Pemupukan melalui daun seringkali tidak berhasil dengan sempurna, hal ini disebabkan konsetrasi yang tidak tepat, suhu dan waktu, perlakuan terlalu tinggi atau rendah, penyemprotan yang tidak merata dan juga tergantung kesehatan tanaman itu sendiri (Rahardjo, 2011). Diduga konsentrasi yang terlalu rendah menyebabkan sebagian besar hasil penelitian menjadi tidak berpengaruh nyata. 


\section{KESIMPULAN DAN SARAN \\ Kesimpulan}

1. Pemberian ZPT Dekamontidak berpengaruh nyata terhadap tinggi tanaman, jumlah daun, lebar daun dan panjang daun, tetapi berpengaruh nyata terhadap diameter batang umur 30 dan 60 HST.

2. Pemberian pupuk daun Gandasil tidak berpengaruh nyata terhadap tinggi tanaman, diameter batang, jumlah daun, luas daun dan panjang daun pada semua umur.

\section{Saran}

Perlu dilakukan penelitian lebih lanjut tentang pengaruh penggunaan ZPT Dekamon dan pupuk daun Gandasil pada dosis yang lebih tinggi.

\section{DAFTAR PUSTAKA}

Cahyono, B. 2010. Sukses Bertanam Cokelat. Pustaka Mina. Jakarta.

Direktorat Jenderal Perkebunan, 2011. Statistik Perkebunan Tahun 2009-2011. Pusat Data dan Informasi Pertanian, Kementerian Pertanian. Jakarta

Lingga, P dan Marsono. 2004. Petunjuk Penggunaan Pupuk. Jakarta : Redaksi Agromedia.
Rahardjo. 2011. Menghasilkan Benih dan Bibit Kakao Unggul. Penebar Swadaya. Jakarta.

Siregar. 2014. Budidaya Coklat. Cetak 4. Penebar Swadaya, Jakarta.

Suhadi,O.2002.PengaruhPemberianUnsurSeng( Zn)danBoron(B)padaBagianTanamanya ngBerbedaTerhadapHasilBuahKakao(Th eobromacacaoL.)padaMusimKemarau. [S kripsi]Bogor:FakultasPertanianInstitutPer tanianBogor.

Suherman, C. 2007. Pengaruh Campuran tanah Lapisan Bawah (subsoil) dan TKKS kompos Sebagai Media tanam Terhadap pertumbuhan Bibit Kelapa sawit (Elaeis guineensis Jacq.) Kultivar Sungai pancur 2 (SP 2) di pembibitan Awal. Universitas Padjajaran. Jurnal Peragi tahun 2007.

Witjaksana. 2000.Pengaruh Bahan Organik Terhadap Sifat Tanah dan Pertumbuhan Tanaman. Jurnal Penelitian Bahan Organik 